\title{
Chemometric Resolution for Baseline Identification of Amomum subulatum Roxb. Essential Oils through FT-IR Spectroscopy Technique
}

\author{
Arvind K. Bhandari ${ }^{*}$, Mamta Baunthiyal2 ${ }^{2}$, Vinod K. Bisht' ${ }^{1}$, Jagdiesh C. Kaim¹, Bir S. Negi ${ }^{3}$ \\ ${ }^{1}$ Herbal Research and Development Institute, Gopeshwar, India \\ ${ }^{2}$ Department of Biotechnology, G.B. Pant Engineering College, Pauri-Garhwal, India \\ ${ }^{3}$ Department of Horticulture, Government of Uttarakhand, Circuit House, Dehradun, India \\ Email: *arvindbhandari2001@yahoo.co.in
}

How to cite this paper: Bhandari, A.K. Baunthiyal, M., Bisht, V.K., Kaim, J.C. and Negi, B.S. (2017) Chemometric Resolution for Baseline Identification of Amomum subulatum Roxb. Essential Oils through FT-IR Spectroscopy Technique. International Journal of Organic Chemistry, 7, 319-324.

https://doi.org/10.4236/ijoc.2017.74026

Received: June 19, 2017

Accepted: November 17, 2017

Published: November 20, 2017

Copyright @ 2017 by authors and Scientific Research Publishing Inc. This work is licensed under the Creative Commons Attribution International License (CC BY 4.0).

http://creativecommons.org/licenses/by/4.0/

\begin{abstract}
Essential oil of Amomum subulatum is the complex mixture of various alkyl, alkanes, sulfonates, amines, alcohols, sulfoxides, trans $\mathrm{RCH} \equiv \mathrm{CHR}$ and aromatic bending compounds. The FT-IR analysis of aromatic bending occurs on $845 \mathrm{~cm}^{-1}$ with para C-H bend. A strong absorption band between $900 \mathrm{~cm}^{-1}-675$ $\mathrm{cm}^{-1}$ indicated the presence of aromatic $\mathrm{C}=\mathrm{C}$. The alcoholic stretching detected on $1080 \mathrm{~cm}^{-1}$ and $1169 \mathrm{~cm}^{-1}$ with C-O stretching molecular motion in large cardamom. In our investigation, the frequency of $2943 \mathrm{~cm}^{-1}$ and 2934 $\mathrm{cm}^{-1}$ the $\mathrm{C}-\mathrm{H}$ stretching occurred in alkyl group. The wave numbers of bands $2966\left(\mathrm{C}=\mathrm{CH}_{2}\right), 1358$ (S=O Stretch), 1215 (C-N Stretch), 1053 (S=O Stretch) and 984 (C-H Bending) the functional group specify vinyl, sulfonates, amines, sulfoxides and trans $\mathrm{RCH}-\mathrm{CHR}$, respectively.
\end{abstract}

\section{Keywords}

Essential Oil, 1,8 Cineole, FTIR, Spectra

\section{Introduction}

Amomum subulatum Roxb. belongs to the family Zingiberaceae is well adopted to cultivation in the hilly areas of Uttarakhand, India [1] and other states such as Sikkim, West Bengal [2]. It is mainly cultivated as spice however, also possesses several medicinal properties such as carminative, stomachic, diuretic and cardiac stimulant [1]. The essential oil yield was reported to be between $2.5 \%$ to $3 \%$ for 
the cardamom grown in different agro-climatic regions of Uttarakhand [1], which contains 31 compounds with 1,8 Cineole as major compound.

Terpenoids, aldehydes, ketones, alcohols and esters were the main compounds present in essential oil. Several methods have been developed for the isolation and identification of compounds present in the essential oil such as Supercritical Carbon Dioxide Extraction (SCDE), Gas Chromatography Mass Spectrometer (GC-MS) and Fourier Transform Infra Red Spectroscopy (FT-IR). FT-IT is a technique through which the functional group presents was determined through comparing the vibration frequencies in wave numbers of the sample spectrograph with those of the IR correlation chart [3]. Identification through FT-IR technique is an advanced chemometric resolution technique through which primary identification of compounds present in essential oil has become possible. Furthermore, this technique is also used for the analysis of unresolved peaks using multivariate curve resolution [4].

Keeping this in view, the present study was designed to identify the presence of 1,8 Cineole in the A. subulatum essential oil grown in different agro-climatic regions of Uttarakhand, India. This is the base-line information on presence of 1,8 Cineole in A. subulatum essential oil.

\section{Material and Methods}

\subsection{Collection and Identification of Plant Materials}

The capsule of the large cardamom was collected during the month of October-November from different agro-climatic regions of Uttarakhand viz. Guhad (Chamoli), Kwiti (Pithoragarh), Lamgarha (Almora), Mandal (Chamoli), Parkandi (Rudraprayag), Sema (Tehri) and Singot (Uttarakashi). The plant was identified by Botanical Survey of India, Dehradun, India with the Accession number 117,262.

\subsection{Oil Extraction}

The dried whole capsules were subjected to hydro-distillation for extraction of essentials oils using Clevenger apparatus for 6 hours at a temperature of $90^{\circ} \mathrm{C}$. The collected concentrated oil was then subjected to anhydrous sodium sulphate to remove the moisture contents and then stored at $4^{\circ} \mathrm{C}$ for further analysis.

\subsection{Standard Solution}

Pure standard compound of 1,8-cineole $\left(\mathrm{MF} \mathrm{C}_{10} \mathrm{H}_{18} \mathrm{O}\right.$, MW $154.3 \mathrm{~g} / \mathrm{mol}$, Assay 98\%) was purchased from HWI Analytik, Germany.

\subsection{Fourier Transforms Infrared Spectroscopy (FT-IR) Technique}

The ATR-FT-IR spectra were recorded in a range between $8500-485 \mathrm{~cm}^{-1}$ using a FT-IR (Make: Horizon MB, spectrometer and detector; Model 114,690 - 131,082, TGS, apodization Cosine, Make-Horizon MS and S.No-1405772-001). Essential oil $5-10 \mathrm{ml}$ was placed on the surface of the diamond ATR crystal. The spectral 
data were processed with Horizon MB Spectra software. Samples were scanned at $4 \mathrm{~cm}^{-1}$ resolution, accumulation: 100 scans.

\section{Results and Discussions}

The structure of 1,8 Cineole is provided in Figure 1. The FT-IR analysis of the essential oil of $A$. subulatum revealed the presence of different functional group such as, alkyl, vinyl, alkanes, sulfonates, amines, alcohol and sulfoxides (Table 1, Figure 2). The functional groups present in essential oil were determined through evaluating the vibration frequencies in wave numbers of the sample spectrograph obtained from FT-IR spectrophotometer with those of a correlation with IR table. The vibration frequencies of the solvent were also obtained to aid in the determination of sample vibration frequencies. The saturated hydrocarbon C-H stretching absorption occurs below $3000 \mathrm{~cm}^{-1}$. The alcoholic stretching detected on $1080 \mathrm{~cm}^{-1}$ and $1169 \mathrm{~cm}^{-1}$ with C-O stretching molecular motion in large cardamom. The position of the $\mathrm{C}=\mathrm{C}$ stretching frequency does vary

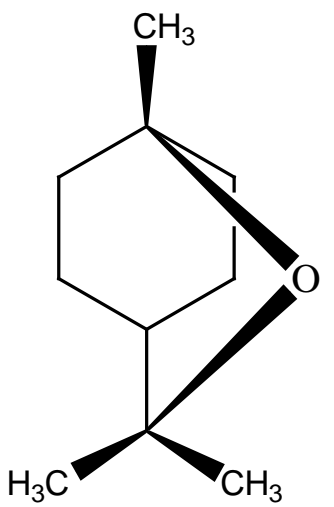

Figure 1. Structure of 1,8 Cineole.

Table 1. Wave number of band with molecular motion in vibration assignments for oils essential oils of $A$. subulatum (Roxb.)

\begin{tabular}{ccc}
\hline Wave number of bands $\left(\mathrm{cm}^{-1}\right)$ & Molecular motion & Functional group \\
\hline 2966 & $\mathrm{C}=\mathrm{CH}_{2}$ & Vinyl \\
2943 & C-H Stretch & Alkyl \\
2924 & $\mathrm{C}-\mathrm{H}$ Stretch & Alkyl \\
1377 & $\mathrm{CH}_{3}$ Bend & Alkanes \\
1358 & $\mathrm{~S}=\mathrm{O}$ Stretch & Sulfonates \\
1215 & $\mathrm{C}-\mathrm{N}$ Stretch & Amines \\
1169 & $\mathrm{C}-\mathrm{O}$ Strong & Tertiary alcohol \\
1080 & $\mathrm{C}-\mathrm{O}$ Stretch & Primary alcohol \\
1053 & S=O Stretch & Sulfoxides \\
984 & C-H Bending & trans RCH $=\mathrm{CHR}$ \\
845 & C-H Bend (para) & Aromatic Bending \\
\hline
\end{tabular}




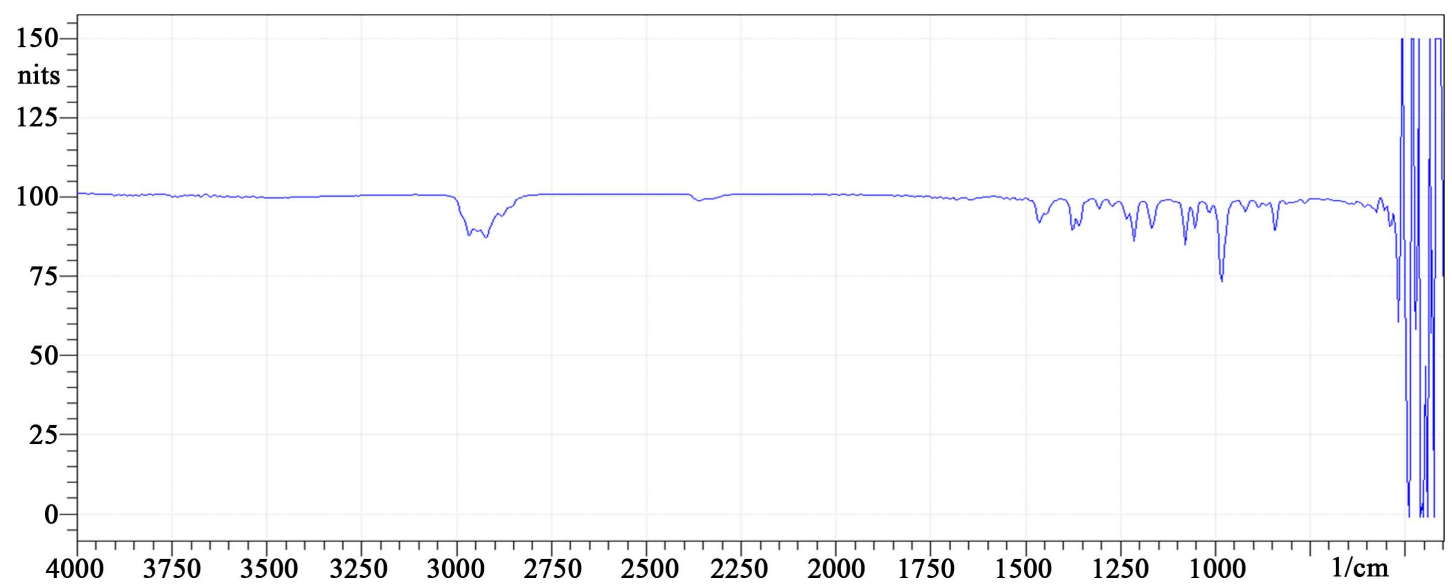

(a)

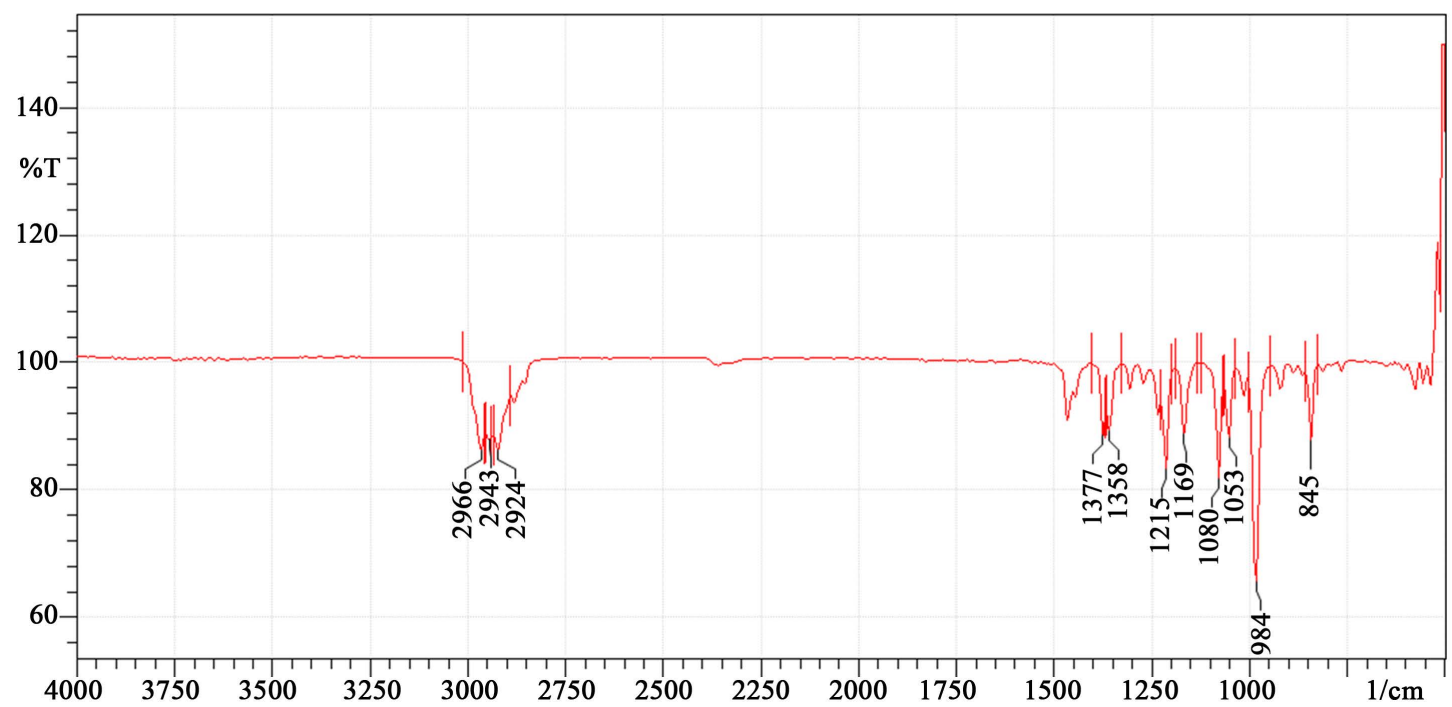

(b)

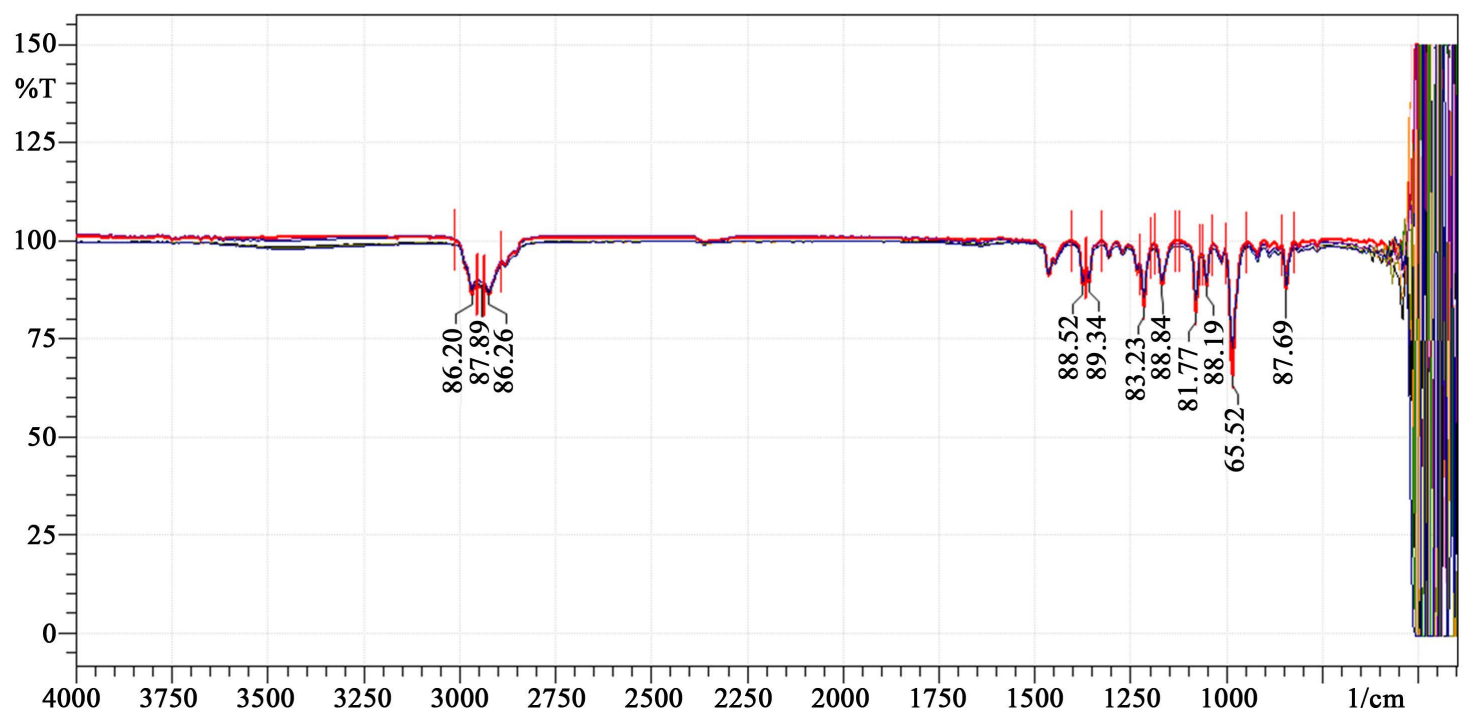

(c)

Figure 2. FT-IR spectra of $A$. subulatum: (a) Spectra of $A$. subulatum oil sample; (b) 1,8 cineole spectra; (c) Overlay spectra of 1,8 cineole and $A$. subulatum oil sample of different sites. 
slightly as a function of orientation around the double bond, but it is less informative than the $\mathrm{C}-\mathrm{H}$ information. Aromatic bending occurs on $845 \mathrm{~cm}^{-1}$ with para $\mathrm{CH}$ bend. A strong absorption band between $900 \mathrm{~cm}^{-1}$ to $675 \mathrm{~cm}^{-1}$ indicated the presence of aromatic $\mathrm{C}=\mathrm{C}$. The absorbance band at $1377 \mathrm{~cm}^{-1}$ revealed the presence of $\mathrm{CH}_{3}$ bond for alkanes. From the spectra we can see clearly that although they show substantial overlap of each absorption spectrum of various components, each band represents an overall overlap of some characteristic absorption peaks of functional groups in the samples. Therefore, FT-IR spectrum reflecting objectively the panorama of chemical constituents in complex system is a most credible method to validate and identify the mix-substance systems such as traditional medicine and herbal medicine [5]. It is observed in present study that the C-H stretching occurred in alkyl group between the frequency of $2943 \mathrm{~cm}^{-1}$ and $2934 \mathrm{~cm}^{-1}$. The wave numbers of bands $2966\left(\mathrm{C}=\mathrm{CH}_{2}\right), 1358$ (S=O Stretch), 1215 (C-N Stretch), 1053 ( $\mathrm{S=O}$ Stretch) and 984 (C-H Bending) the functional group occurs Vinyl, sulfonates, Amines, sulfoxides and trans $\mathrm{RCH}$ $\equiv$ CHR found respectively (Table 1, Figure 2). The result of the FT-IR analysis of essential oil of $A$. subulatum of seven different sites were found relatively identical for the 1,8 cineole compound (Figure 1). Earlier studies on essential oil of $A$. subulatum also revealed the presence of 1,8 cineole as a major compound [1] [5]. Many workers applied the FT-IR spectrum as a tool for differentiating, classifying and discriminating closely related plants and other organisms [6] [7]. Thus, finding of the present work on A. subulatum oils is used as analytical tool to check not only the primary identification of the compounds present in oils but also help in to further examine those compounds for their biological properties.

\section{Conclusion}

The results of the present study revealed the presence of 1,8-cineole in all the essential oils analyzed. Vinyl, alkyl, alkanes, sulfonates, amines, alcohols, sulfoxides, trans $\mathrm{RCH} \equiv \mathrm{CHR}$ are the other important functional groups identified in the essential oil of $A$. subulatum grown in different agro-climatic regions of Uttarakhand, India.

\section{References}

[1] Bhandari, A.K., Baunthiyal, M., Bisht, V.K., Negi, B.S. and Kaim, J.C. (2017) Assessment of Intra-Specific Variation in Essential Oil Composition in Amomum subulatum Roxb. Cultivated in Uttarakhand, India. Asian Journal of Chemistry and Pharmaceutical Sciences, 2, 1-5.

[2] Balakrishnan, K.V., George, K.M., Mathulla, T., Pillai, Narayana, O.G., Chandran, C.V. and Verghese, J. (1984) Studies in Cardamom-1, Focus on Oil of Amomum subulatum Roxb. Indian Spices, 21, 9-12.

[3] Madivoli, S.E., Gitu, L. and Gumba, E. (2012) Isolation and Identification of Essential Oils from Cymbopogan citrates Dc Using GC-MS and FT-IR. Chemistry and Materials Research, 2, 13-22.

[4] Heravi-Jalali, M., Moazeni Sadat, R. and Sereshti, H. (2011) Analysis of Iranian Ro- 
semary Essential Oil: Application of Gas Chromatography-Mass Spectrometry Combined with Chemometrics. Journal of Chromatography A, 1218, 2569-2576. https://doi.org/10.1016/j.chroma.2011.02.048

[5] Bhandari, A.K., Bisht, V.K., Negi, J.S. and Baunthiyal, M. (2013) 1,8-Cineole: A Predominant Component in the Essential Oil of Large Cardamom (Amomum subulatum Roxb.). Journal of Medicinal Plants Research, 7, 1957-1960.

[6] Liu, H., Sun, S., Lv, G. and Chan, K.K.C. (2006) Study on Angelica and Its Different Extracts by Fourier Transform Infrared Spectroscopy and Two-Dimensional Correlation IR Spectroscopy. Spectrochimica Acta Part A, 64, 321-326.

https://doi.org/10.1016/j.saa.2005.07.026

[7] Lamprell, H., Mazerolles, G., Kodjo, A., Chamba, J.F., Noel, Y. and Beuvier, E., (2006) Discrimination of Staphylococcus aureus Strains from Different Species of Staphylococcus Using Fourier Transform Infrared (FTIR) Spectroscopy. International Journal of Food Microbiology, 108, 125-129.

https://doi.org/10.1016/j.ijfoodmicro.2005.10.015 